\title{
Developing adult motivation for continuous training
}

\author{
Elena Lucia Mara $^{1 *}$ \\ ${ }^{1}$ University "Lucian Blaga” of Sibiu, Department of Teacher Training, Calea Dumbrăvii 34, Sibiu, \\ Romania
}

\begin{abstract}
Traditional education focused primarily on the moment of teaching, on the moment of transmitting information, knowledge, and only then on aspects related to ethical, motivational, moral nature. Contemporary society in a continuous remodeling and change, no longer coincides, no longer accepts such a system. Traditional learning does not keep pace with contemporary society. The aim of this study is to investigate the motivation of learning in adulthood. In the motivational structure of the investigated adults, extrinsic reasons predominated, indirectly related to the learning activity, such as: the need to advance professionally, to keep up with the times, to obtain a social status as high as possible, to meet current requirements, to earn the respect of others, for a diploma, a change of job. Among the intrinsic reasons invoked by the study participants, directly related to the learning activity, we mention: the desire for knowledge and personal development, curiosity, the desire to teach others. In conclusion, we want to offer a better perspective and a well-understanding of motivational factors implicated in adult learning, ensuring the ease of triangulation of sources of information collection, thus improving the credibility of findings.
\end{abstract}

\section{Introduction}

The term "adult education" is relatively new, although historically, the Committee on Adult Education was founded in 1919 in the United Kingdom. Education, as a social process, accompanies an individual throughout his life, helping him to develop intellectually, axiologically, emotionally but also to be able to constantly adapt to the increasingly complex requirements of society. The idea of a need for education, regardless of age, is not new. For example, in sec. XVII, Jan Amos Comenius (philosopher, grammarian and pedagogue of Czech origin, the father of modern education), in his work "Didactica Magna" stated that pedagogy can never be restricted to school or family education, it concerns the entire existence of the individual thus emphasizing the need and necessity of a permanent, continuous and universal education. Adult pedagogy is beginning to develop and grow since the 1930s. In the language of educational sciences, the term "adult education" entered especially after 1960, when the role of specific institutions and research

\footnotetext{
* Corresponding author: lucia.mara@ulbsibiu.ro
} 
for such a problem enjoyed a high interest. There was more and more talk about adult education, about their improvement, recycling and even about specific universities for the elderly. Gradually, adult education is undergoing fundamental changes, some of which are still being experienced today. For many centuries in a row there has been a belief that human education is achieved in the first part of life, ie only childhood. In fact, it is considered that there are three major periods of human life, respectively: childhood dominated especially by education; maturity - predominant majority of work; old age which was perceived as a preparation for leaving this world. Gradually, the period of the industrial revolution fundamentally and irremediably changed the entire content of a person's life, education being forced to extend far beyond childhood. But the strong development of university education in the twentieth century. XIX and the beginning of the century. XX shows that there is a need for improvement and education to continue into adulthood. The first International Adult Conference was held in 1949 in Elseneur, Denmark. Then, after a terrible economic, social, educational disaster that was represented by the Second World War, the world community felt the need to lean on "moral reconstruction", to restore peace and harmony between different cultures and nations, and restore confidence in humanity. Following this first conference, the following general objectives were established in terms of adult education, namely: promoting and supporting movements for a mass-based culture; stimulating the democratic spirit and returning to the community spirit. Over time, others have been added to this primitive list of objectives, such as: development of individual personality throughout life; facilitating participation in an active socio-economic life; elimination of inequalities caused by the initial education system; better development of creativity.

\section{Adult education}

It is important to remember that adult education addresses all social categories, this actively contributing to the optimal integration of individuals themselves, ending, in the end, as a factor in democratizing social life and as a means of respecting the right to education. Specifically, adults can be mentioned for their varied employment in a wide range of roles. Paradoxically and contrary to previous opinions, it was found that this active employment in multiple social roles does not facilitate change at all, but, on the contrary, leads to an inertia in relation to change. In other words, the adult does not readily accept the change because this implies a structural change of the whole explanatory, value and action model. Change is possible only from what is useful and accessible. An extremely important aspect that must be taken into account refers to the degree of participation in adult education, in the sense of an education that arises from the participation of the masses of people, at a given time at different stages of social and professional development and operating with specific symbols and cultural meanings. The above theory brings to the surface a new, deeper meaning of the act of education, namely that of major expansion of valuable human activity in relation to man. The major imperative of the contemporary era is to learn, to think, to feel and to work in a creative, new way. Therefore, adult education also considers:

- Compensating for an outdated / deficient / insufficient initial education;

- Completing general knowledge;

- Continuous training and development.

Adult learning tends to move away from the traditional pedagogical teaching method to capitalize on the individual characteristics of the adult. The existence of specific technologies for adult learning requires the need to provide clarification on this learning. Accepting the andragogical way of learning imposes on the teacher the obligation to take into account, for the elaboration of the technology, the following aspects:

- The physical environment in which the act of learning takes place must be such as to make adults feel unhindered; 
- The psychological climate should be one in which adults feel accepted, respected and supported. It is necessary to have a spirit of mutual respect and collaboration between teachers and trainees, to exist and to predominate freedom of expression without fear of being ridiculed. The individual tends to feel "mature" in a benevolent and informal environment;

- The behavior and behavior of the teacher directly influences the character of the study activity more than any other factor taken separately;

- Given that adults themselves are a rich source for study, the main focus should be on the techniques that make use of their experience (participatory training methods stimulate participation in the learning environment). The andragogical paradigm requires that educational techniques start from the differences that may exist between children and adults in the learning process:

Table 1. Learning process

\begin{tabular}{|c|c|}
\hline Children & Adults \\
\hline $\begin{array}{l}\text { Other people decide for themselves what is } \\
\text { important to be learned }\end{array}$ & $\begin{array}{c}\text { They decide for themselves what is important to } \\
\text { learn }\end{array}$ \\
\hline $\begin{array}{l}\text { Accept the information received without } \\
\text { questioning its content and reality }\end{array}$ & $\begin{array}{l}\text { I feel the need to validate the information } \\
\text { received based on my own experience and } \\
\text { opinions }\end{array}$ \\
\hline $\begin{array}{l}\text { What they learn is expected to be useful to them } \\
\text { in the distant future }\end{array}$ & $\begin{array}{l}\text { What they learn is expected to be useful to them } \\
\text { in the nearest future }\end{array}$ \\
\hline They have no preconceived notions & Experience can fix certain preconceived ideas \\
\hline $\begin{array}{l}\text { In most cases, they cannot be sources of learning } \\
\text { for teachers or colleagues }\end{array}$ & $\begin{array}{l}\text { They can be a source of learning for both } \\
\text { teachers and colleagues to a large extent }\end{array}$ \\
\hline They are focused on the content and the present & They are focused on the problem \\
\hline They are less actively involved & Participate actively \\
\hline Planning is the teacher's responsibility & $\begin{array}{l}\text { Planning is a shared responsibility between the } \\
\text { teacher and the students }\end{array}$ \\
\hline Learn well in a more authoritarian environment & Learn well in a collaborative environment \\
\hline
\end{tabular}

Adult education aims at the symmetrical development of all the social roles that any individual can play: professional, family, civic and cultural. The learning process in andragogy refers to the change of knowledge, skills and experience of those trained. The main problem of any training is to create an environment that stimulates and maximizes their opportunities in the learning process. For this, it is clear that we need to know the characteristics of the adult-specific learning process:

- Adults are students who are oriented towards their own person. As we mature and increase our ability to use the experience gained during the learning process and to organize this process to solve everyday problems;

- Adults are predominantly active participants. In the learning process, adults will not be passive participants, a characteristic aspect of the formal education process, but will be predominantly active;

- Adults tend to validate new information. They will try to filter them through their own standards and experiences and only then will they accept them;

- Adults learn through collaboration. These are not empty vessels to be filled with knowledge and skills by an all-knowing teacher. 


\section{Adult learning theory}

The idea of lifelong learning puts us in front of many perspectives of study and research on the problems of motivation to learn in adulthood. The most common perspective in the pedagogical-andragogical literature of the last decade of the twentieth century and beginning of the twenty-first century is the point of view of socio-cultural and economic determinism of the development of cognitive abilities, aptitudes and attitude of the individual throughout life. The change of appearance, as well as the strategic one from the pedagogical, psycho-physiological and sociological dimensions of the study of adult learning to the socio-cultural, economic and, more recently, managerial ones is mainly reduced to the evolution of economic and social conditions. Globalization, cultural evolution, unemployment, the diversity of the public who are offered educational opportunities are mentioned by Adrian Neculau as "new challenges that can lead to reformulating the objectives of adult education: from offering a" second chance "to stopping" the accumulation of inequalities"[1]. The stimulating synergy of the idea of education throughout life generates conjugate effects at the level of individual, system and society.

Table 2. Conjugate effects in education

\begin{tabular}{|l|l|l|}
\hline Individual effects & Systematic effects & Social effects \\
\hline -Reduction of marginalization & -Functioning of staff & -The active members in the \\
- Developing the ability to & specialization systems- & society \\
"learn to learn"-Positive aspect & Recognition of the quality of & -Raising the entrepreneurial \\
on learning & work as one of the basic & spirit \\
& resources of the economy & -Increasing the life expectancy \\
& -the interpenetration between \\
the training structures & \\
\hline
\end{tabular}

The idea of "lifelong learning" supports the concept of an integrated model of learning and an abstract model of adult motivation to learn, developed based on the general principles of learning, human physiological and psychosocial characteristics, social demands, including of managerial visions on professional activities. The ultimate goal of continuing education is to increase and improve the quality of life. To ensure this goal, the motivational valences of the concept of lifelong learning derive from the "universal character", the "vertical articulation" and the "horizontal integration" of education. According to the specifications of the concept, the family, the community and the educational institutions generate all the formative interventions on the human being "from the cradle to the end of life". In terms of educational policies at European level, the essence of the motivational approaches of the concept consists in the following principles:

- General quality basic education is the essential basis of lifelong learning process;

- The level of education demand must increase at the same time as supply;

- The "lifelong" dimension emphasizes more strongly the complementarity of formal, non-formal and informal learning process;

- Current policies combine social and cultural objectives with rational economic reasoning in favor of lifelong learning [2].

In this order of ideas, there are at least two important factors for identifying the motivational aspects of learning at adult levels, combined at the level of the psychological concept of motivators and the motivational approach, respectively the context and availability. Another conceptual delimitation with references to the motivational approaches of lifelong learning is based on the controversy regarding the staged, cyclical or 
continuous character of development. The characteristics of the concept of education and continuous training, determined by development theories, are the following:

- Education does not end at the end of institutionalized schooling but is an ongoing process. Lifelong learning extends throughout the life of an individual;

- Lifelong learning is not limited to adult education, and includes and unifies all aspects of education: preschool, primary, secondary, etc. thus, it seeks to approach education in its entirety, its totality;

- Lifelong learning is a dynamic approach to education that allows the evolution of materials and means of learning to the new conditions imposed by development.

The term motivational approach is a synthetic one and is not approached neither in the psychological literature, nor in the pedagogical / andragogical one. Starting from the meaning of the word approach which means "intervention in order to obtain a result" [3], from the concept of pedagogical approach which represents the set of formative interventions directed, especially by the educator (teacher, parent, etc.) in order to optimize the didactic / educational action "[4], from the psychological concept of extrinsic motivation and the notion of motivator as" psychological factor of the motivational process that participates in a certain motivational process and determines the personal decision"[5], we can formulate the following definition of the motivational approach to adult learning from the aspect of the concept of lifelong learning: "the set of formal, non-formal and informal motivating interventions that maintain human willingness to learn throughout life or determine adult decision to get involved in the learning activity whenever he feels this need".

Motivational approaches to adult learning can be classified according to the direction, intention and content of the influence. Thus, we can conclude that the motivational approaches to adult learning from the perspective of the concept of lifelong learning are the following:

- Anticipative;

- Current;

- Futurological.

\section{Conclusions}

Adult learning is primarily conditioned by their motivation. The success of learning depends on factors such as the plausibility of the action (the degree of valorization of the learning approach), the action potential, the permissiveness of the environment, but also others, such as the quality of the curriculum and the teaching act, all these factors being identified. Another aspect that emerged is the availability of adults for learning stimulates their ability to learn. Also, this availability depends in turn on the ability of the environment to stimulate their interest. Many of adults encountered difficulties in identifying the reasons why they are learning, however, the adults appreciate their need for learning as high. In the motivational structure of the investigated adults, extrinsic reasons predominated, indirectly related to the learning activity, such as: the need to advance professionally, to keep up with the times, to obtain a social status as high as possible, to meet current requirements, to earn the respect of others, for a diploma, a change of job. Among the intrinsic reasons invoked by the study participants, directly related to the learning activity, we mention: the desire for knowledge and personal development, curiosity, the desire to teach others. This study provides a perspective and a better understanding of the motivational factors involved in adult learning. This understanding, both by trainers and those responsible for education, has the potential to improve the involvement of adults in lifelong learning and training. In addition, this study provides a useful starting point for future research. A possible future direction of research may be the investigation of the link between motivational factors and 
emotional intelligence. Goleman explains emotional intelligence as a manifestation of "abilities, such as the ability to self-motivate and cope with frustrations; impulse control and deferral of gratuities; to adjust one's mood and to keep one's distance at bay so as not to affect one's ability to think; to empathize and hope" [6]. Goleman suggests that our level of emotional intelligence determines the potential to learn and identify in this regard 4 fundamental pillars of emotional intelligence, namely: self-awareness; social awareness, self-management and the ability to manage relationships. It is necessary to conduct research to see to what extent these fundamental factors, these four pillars identified, influence the mood of adults and their learning potential. Behavioral cues resulting from inter- and intrapersonal intelligences are emotionally linked and tend to influence learning and success. The benefit of such a study would be to help teachers, trainers to properly identify their own emotional challenges and also to develop coping strategies and carefully develop intervention techniques to improve motivation. adults to learn.

\section{References}

1. Bocoș, M. Theory and practice of pedagogical research, (Casa Cărții de Știință Publishing House, Cluj-Napoca, 2003).

2. Cucoș, C. (coord.). Psychopedagogy for final exams and teaching degrees. 3rd edition revised and added, (Polirom Publishing House, Iasi, 2009)

3. Coteanu, I, Seche, L, Seche, M. Explicative dictionary of Romanian language, (Univers Enciclopedic Publishing House, Bucuresti,1996).

4. Zlate, M. Cognitive mechanism psychology. (Polirom Publishing House, Iasi, 1999).

5. Cristea, S. Fundamentals in pedagogy, (Polirom Publishing House, Iasi, 2018)

6. Goleman, D. Emotional intelligence, (Curtea Veche Publishing House, Bucuresti, 2018). 